\title{
Arquitetura da copa do cafeeiro arábica conduzido com diferentes números de ramos ortotrópicos ${ }^{1}$
}

\author{
Tafarel Victor Colodetti ${ }^{*}$, Marcelo Antonio Tomaz, ${ }^{3}$, Wagner Nunes Rodrigues ${ }^{2}$, Abraão Carlos Verdin Filho ${ }^{4}$, \\ Paulo Cezar Cavatte ${ }^{5}$ Edvaldo Fialho dos Reis ${ }^{6}$
}

\section{$10.1590 / 0034-737 X 201865050006$}

\begin{abstract}
RESUMO
O estudo do comportamento do cafeeiro arábica conduzido com mais de um ramo ortotrópico surge como fonte de alternativas de melhoria da arquitetura da copa e da produção da lavoura cafeeira. Por isso, objetivou-se, com este trabalho, analisar a arquitetura da copa do cafeeiro arábica conduzido com diferentes números de ramos ortotrópicos por planta. Um experimento foi realizado em campo, no município de Santa Teresa, ES, em altitude de $740 \mathrm{~m}$, topografia ondulado-acidentada, com precipitação e temperatura média anual de $1.282 \mathrm{~mm} \mathrm{e} 21,1^{\circ} \mathrm{C}$, respectivamente. O espaçamento foi de 2,5 x 1,0 m e o cultivar foi o Catuaí Vermelho IAC44. Em novembro de 2012, aos oito anos de idade, a lavoura foi recepada e as brotações que surgiram foram conduzidas para promover o estabelecimento de três tratamentos referentes ao número de ramos ortotrópicos: um, dois ou três ramos por planta. O experimento seguiu delineamento em blocos casualizados, com oito blocos e os três tratamentos. Plantas de cafeeiro arábica com dois ou três ramos ortotrópicos não se diferiram e apresentaram maior área e volume de copa, densidade de enfolhamento e área foliar dos ramos plagiotrópicos. A condução do cafeeiro arábica com dois ramos ortotrópicos por planta proporcionou maior produção de café beneficiado por hectare, bem como maior proporção de grãos graúdos (grãos maiores e com massa mais homogênea).
\end{abstract}

Palavras-chave: Coffea arabica; manejo de poda; produtividade; adensamento.

\section{ABSTRACT \\ Canopy architecture of arabica coffee conducted with different numbers of orthotropic branches}

The study on the behavior of Arabica coffee trees cultivated with more than one orthotropic branch appears as an alternative to improve canopy architecture and may enhance coffee crop yield. In this context, the objective of this study was to analyze traits of canopy architecture of Arabica coffee trees cultivated with different numbers of orthotropic branches per plant. For this end, an experiment was carried out in a productive field located in Santa Teresa, ES, Brazil, at an altitude of $740 \mathrm{~m}$, with wavy-rugged topography, and annual rainfall and average air temperature of 1,282 $\mathrm{mm}$ and $21.1^{\circ} \mathrm{C}$, respectively. The spacing between plants was $2.5 \times 1.0 \mathrm{~m}$, and the cultivar used was Catuaí Vermelho IAC44. In November 2012, the plants at eight years of age were pruned, and the new emerged sprouts were conducted to promote the establishment of three treatments regarding the number of orthotropic branches: one, two, or three branches per plant. The experiment followed a randomized block design, with eight blocks and three treatments. The coffee plants grown with two or three orthotropic branches did not differ and presented larger canopies in area and volume, larger

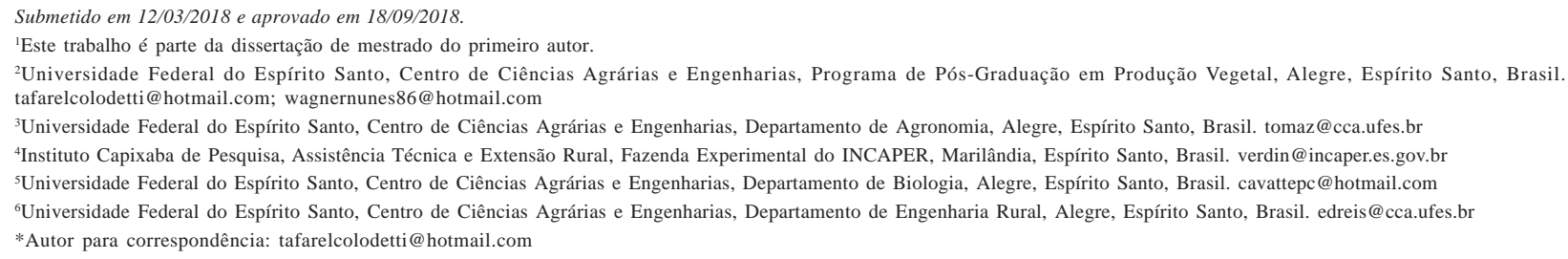


foliage density, and leaf area of their plagiotropic branches. The conduction of the Arabica coffee trees with two orthotropic branches per plant promoted greater production of processed coffee per hectare, as well as greater proportion of large grains (resulting in larger grains and a more homogeneous mass).

Keywords: Coffea arabica; pruning management; crop yield; plant density.

\section{INTRODUÇÃO}

Uma lavoura de café arábica é considerada eficiente quando consegue sustentar um extenso e iluminado dossel, com alta taxa fotossintética, resultando em alta capacidade de produção e de formação de frutos. A técnica do adensamento, por exemplo, pode estar associada com a obtenção dessas características em lavouras cafeeiras, visto que é capaz de provocar alterações no ambiente da lavoura, que acarretam modificações nos padrões fisiológicos, morfológicos e produtivos (Rena et al., 1994). Porque se baseia na elevação do número de plantas por área, o adensamento possibilita, juntamente com um conjunto de outras técnicas, a obtenção de incrementos consideráveis de produtividade (Braccini et al., 2005), por utilização mais eficientemente da radiação solar incidente e exploração de maior volume de solo e, consequentemente, mais capacidade de absorção de água e nutrientes (Carvalho et al., 2013).

A diminuição do espaçamento entre as plantas, ocasionada pelo adensamento, pode refletir em crescimento acentuado do ramo ortotrópico (Rena et al., 1994) e, possivelmente, na morte de ramos plagiotrópicos, na região inferior da copa das plantas (saia do cafeeiro), por causa do sombreamento excessivo (Thomaziello et al., 1998; Matiello et al., 2002). Tudo isso pode resultar, ao longo dos anos, na diminuição do vigor das plantas e da produtividade, aumento da competição entre plantas pelos substratos básicos ao crescimento, entre outros (Carvalho et al., 2006; Oliveira et al., 2007; Pereira et al., 2007). De acordo com Cunha et al. (1999), a poda é uma das alternativas mais viáveis e válidas para reverter o processo de depauperamento das lavouras.

A poda é uma operação para eliminar partes das plantas que perderam ou diminuíram a capacidade de produção, cuja possibilidade de recuperação natural seja praticamente nula. Com isso, há supressão da dominância apical e do estímulo para a emissão e desenvolvimento de novas brotações a partir de gemas latentes (Thomaziello \& Pereira, 2008), o que resulta na renovação de estruturas produtivas, como ramos ortotrópicos (verticais) e ramos plagiotrópicos (horizontais).

Um estudo do manejo de poda do cafeeiro arábica, focado na produtividade, foi realizado em uma lavoura depauperada com oito anos de idade e com espaçamento de 2,5x1,0 m, que passou por recepa baixa, em 2008, e a brotação conduzida para manter dois ou três ramos verticais por planta. Após as colheitas, os ramos plagiotrópicos do baixeiro da copa foram retirados. Esse estudo mostrou que a condução do cafeeiro arábica com três ramos ortotrópicos e com a retirada dos plagiotrópicos, que já haviam produzido $70 \%$ de sua capacidade, resultou em maiores níveis de produção ao longo de cinco colheitas (Verdin Filho et al., 2016). Dessa forma, o manejo de poda no cafeeiro arábica pôde atuar na recuperação de lavouras depauperadas e promover incrementos de produtividade.

A condução de plantas de cafeeiro arábica com maior número de ramos ortotrópicos ainda é pouco estudada, o que torna necessário o levantamento de informações consistentes e que contribuam para a validação ou não desse manejo. Neste trabalho, objetivou-se analisar a arquitetura da copa e seu reflexo sobre a produtividade do cafeeiro arábica, conduzido com diferentes números de ramos ortotrópicos.

\section{MATERIAL E MÉTODOS}

\section{Caracterização do campo experimental}

O experimento foi realizado no município de Santa Teresa, ES, região Serrana do Estado do Espírito Santo, nas coordenadas geográficas $19^{\circ} 49^{\prime} 05.7^{\prime \prime} \mathrm{S}$ e $40^{\circ} 45^{\prime} 55.6^{\prime \prime}$ O. A altitude do local é de $740 \mathrm{~m}$ e o solo classificado como Latossolo Vermelho-Amarelo distrófico, com topografia ondulado-acidentada. Na classificação de Köppen, o clima da região é do tipo Cwa (subtropical de inverno seco), com precipitação acumulada média anual de $1.282 \mathrm{~mm}$ e temperatura média anual de $21,1^{\circ} \mathrm{C}$. A região do estudo encontra-se na zona apta para o cultivo do cafeeiro arábica (Pezzopane et al., 2012), com produtividade média regional de 26,70 sacas ha-1 . O pico da florada ocorre no mês de setembro e o da colheita no mês de julho (Conab, 2017).

O espaçamento utilizado foi de 2,5x1,0 m, que permitiu uma população de 4000 plantas por hectare, considerado cultivo adensado (Thomaziello \& Pereira, 2008). O cultivar utilizada foi o Catuaí Vermelho IAC44, amplamente empregado em lavouras cafeeiras no Estado do Espírito 
Santo. A lavoura onde o experimento foi implantado apresentava oito anos de idade quando passou por uma poda com recepa baixa, em novembro de 2012. Com a recepa, as plantas iniciaram novas brotações, que foram conduzidas até apresentarem, em média, $20 \mathrm{~cm}$ de altura, momento em que efetuou-se a desbrota e permitiu-se a manutenção de apenas um, dois ou três brotos por planta, ou seja, de acordo com os tratamentos dos diferentes números de ramos ortotrópicos por planta.

Durante o período experimental, que transcorreu entre a recepa (novembro de 2012) e a colheita (junho de 2015), o manejo da adubação foi realizado de acordo com as recomendações para a cultura do café arábica no Estado do Espírito Santo (Prezotti et al., 2007), assim como os tratos fitossanitários e as práticas culturais (Reis \& $\mathrm{Cu}$ nha, 2010). O experimento foi conduzido em condição de sequeiro.

\section{Delineamento experimental}

$\mathrm{O}$ experimento seguiu delineamento em blocos casualizados, com oito blocos e manejo do número de ramos ortotrópicos em três níveis. Os três níveis de manejo consistiram em um, dois ou três ramos ortotrópicos por planta, obtidos da brotação após a recepa. A parcela experimental foi composta por três plantas úteis, delimitadas por uma planta de bordadura em cada extremidade.

\section{Avaliações}

As avaliações ocorreram durante o primeiro ciclo produtivo do cafeeiro após a recepa (safra 2015-16). As avaliações foram realizadas na fase fenológica de maturação dos frutos. De cada uma das três planta úteis da parcela, dois ramos plagiotrópicos de primeira produção foram identificados para realização das seguintes avaliações: comprimento do ramo (CRP; $\mathrm{cm})$, mensurado com trena graduada em milímetros; número de nós (gemas reprodutivas e vegetativas) (NG; unidades), obtido por contagem direta; número de rosetas (NRO; unidade), obtido por contagem direta; comprimento do internódio do ramo (CIRP; cm), obtido pela relação entre o CRP e NG; angulação de inserção dos ramos plagiotrópicos no ramo ortotrópico (ANG; ${ }^{\circ}$ ), obtida com inclinômetro digital, em quatro ramos plagiotrópicos selecionados na parte mediana da copa do ramo ortotrópico mais representativo da planta, e a angulação superior, formada entre este ramo e o caule da planta, foi mensurada.

Após estas análises, os ramos plagiotrópicos marcados foram coletados para realização das demais avaliações: número de frutos por roseta (NFR; unidade), obtido por contagem direta; e área foliar do ramo (AFR; $\mathrm{cm}^{2}$ ), obtida pela coleta e passagem de todas as folhas do ramo no integrador de área foliar "Area meter”, modelo 3100, LiCor.
De cada planta útil da parcela, foi selecionado um ramo ortotrópico representativo da planta, para realização das avaliações: número total de ramos plagiotrópicos na planta (NRP; unidade), obtido por contagem direta; e comprimento do internódio do ramo ortotrópico (CIRO; $\mathrm{cm}$ ), determinado pela relação entre a altura efetiva da copa e a metade de NRP.

Em cada planta útil da parcela, também se avaliaram as seguintes características: altura da planta (ALT; m), por meio de trena graduada em centímetros; área de projeção da copa (AREA; $\mathrm{m}^{2}$ ), por mensuração do diâmetro de copa com trena graduada em centímetros; volume da copa $\left(\mathrm{VOL} ; \mathrm{m}^{3}\right.$ ), utilizando-se o modelo cilíndrico para o cálculo do volume; densidade de enfolhamento (DEN; folhas $\mathrm{m}^{-3}$ ), pela razão entre o número total de folhas da planta (estimado pela multiplicação do número de folhas do ramo plagiotrópico marcado e o NRP) e o volume da copa da planta.

Em junho de 2015, procedeu-se à colheita dos frutos de cada parcela experimental, para estimativa da produção de café beneficiado por hectare (PROD; sacas ha-1). Os frutos foram secados e beneficiados para determinação da produção. De cada parcela experimental, foi coletada uma amostra de café beneficiado (300 g), sendo os grãos submetidos à análise física para determinação da percentagem de café retida em cada classe de peneiras (separação pelo tamanho do grão), com as peneiras 17 acima (P17AC); 15+16 (P15-16); 13+14 (P13-14); 12 abaixo (P12AB).

\section{Análise estatística}

Os dados foram submetidos à análise de variância e na presença de diferenças significativas, foi utilizado o teste de Tukey, para a comparação entre os números de ramos ortotrópicos, a $5 \%$ de probabilidade. A análise dos dados foi realizada com o programa de análise estatística SISVAR (Ferreira, 2011).

\section{RESULTADOS E DISCUSSÃO}

Não se observou efeito significativo sobre as variáveis altura da planta, comprimento do ramo e do internódio do ramo plagiotrópico, comprimento do internódio do ramo ortotrópico e angulação de inserção do ramo plagiotrópico, em função do número de ramos ortotrópicos por planta (Tabela 1). Verificou-se efeito significativo do fator número de ramos ortotrópicos sobre as variáveis: área de projeção da copa, volume da copa, densidade de enfolhamento, número de ramos plagiotrópicos, número de rosetas, número de frutos por roseta, número de nós, área foliar do ramo plagiotrópico e produção de café (Tabela 1), sendo possível observar o comportamento dessas variáveis, em função de cada tratamento, nas Figuras 1, 2 e 3. 
O crescimento em altura (ALT) das plantas manteve $o$ mesmo padrão, independentemente do número de ramos ortotrópicos na planta, o que, juntamente com os dados de comprimento dos internódios do ramo ortotrópico, indica que não ocorreu estiolamento dos ramos ortotrópicos (Tabela 1), pois não se verificou influência significativa do número de ramos ortotrópicos no comprimento dos internódios dos ramos plagiotrópicos (CIRP) e ortotrópi$\cos$ (CIRO) das plantas (Tabela 1).

Observaram-se maiores área (AREA) e volume (VOL) da copa em plantas com dois e três ramos ortotrópicos (Figura 1A, 1B). Um maior dossel, tanto em área como em volume, contribui, até certo nível, para o desenvolvimento das plantas, visto que boa parte do sistema radicular das plantas é proporcional à sua parte aérea. Pode-se inferir que maiores área e volume da copa sejam sustentados por um maior volume de raízes, favorecendo o aumento da capacidade de exploração do solo em busca por água e nutrientes, como embasado por Mota et al. (2006), Alves et al. (2011), Pereira et al. (2011) e Ronchi et al. (2015).

Maior densidade de enfolhamento (DEN) foi observada em plantas com dois e três ramos ortotrópicos (Figura 1C). Essa variável relaciona a quantidade de folhas com o volume de copa da planta. Até certos níveis, o aumento do número de folhas na copa pode formar um microclima capaz de favorecer as trocas gasosas e a fotossíntese na planta. Porém, se ocorrer adensamento excessivo, é possível que haja autossombreamento de folhas mais internas no dossel, o que pode resultar em limitações à fotossíntese (DaMatta \& Rena, 2002; DaMatta et al., 2007).
Não houve diferenciação significativa para o comprimento de ramos plagiotrópicos (CRP) por ramo ortotrópico (Tabela 1). No entanto, observou-se aumento significativo do número de ramos plagiotrópicos (NRP) com o acréscimo do número de ramos ortotrópicos por planta (Figura 1D).

Se a área da copa, o volume da copa e o comprimento do ramo plagiotrópico foram estatisticamente os mesmos, entre plantas com dois e três ramos ortotrópicos, e o número total de ramos plagiotrópicos por planta foi maior no tratamento conduzido com três ramos verticais, infere-se que houve maior adensamento da copa das plantas com três ramos ortotrópicos, além da possibilidade de restrição à entrada de luz no interior do dossel, intensificando o autossombreamento na planta (DaMatta \& Rena, 2002; DaMatta et al., 2007).

Aumentar o número de ramos plagiotrópicos, isoladamente, não necessariamente traz incrementos consideráveis de produtividade (Pavan et al., 1994; DaMatta \& Rena, 2002; DaMatta et al., 2007; Pereira et al., 2011), certamente por efeitos do adensamento desses ramos, na copa, e do autossombreamento de folhas, no dossel.

Mesmo com o aumento do número de ramos ortotrópi$\cos$, não houve alterações na angulação dos ramos plagiotrópicos (ANG), observando-se pequenos ângulos (média de $32,02^{\circ}$ ) de inserção dos ramos plagiotrópicos no ramo ortotrópico (Tabela 1). Esses resultados mostraram que a copa das plantas do cultivar em questão é fechada e compacta, conforme sua descrição (Fazuoli, 1999; Matiello et al., 2010; IAC, 2014). Foi relatado por Sera et

Tabela 1: Resumo da análise de variância das variáveis altura de planta (ALT), área da copa (AREA), volume da copa (VOL), densidade de enfolhamento da planta (DEN), número de ramos plagiotrópicos (NRP), comprimento do ramo plagiotrópico (CRP), comprimento do internódio do ramo ortotrópico (CIRO), comprimento do internódio do ramo plagiotrópico (CIRP), angulação do ramo plagiotrópico (ANG), número de rosetas (NRO), número de frutos por roseta (NFR), número de nós (NG), área foliar do ramo plagiotrópico (AFR) e produção de café beneficiado por hectare (PROD), em função do número de ramos ortotrópicos de plantas de cafeeiro arábica Catuaí Vermelho IAC44 (Santa Teresa, ES, safra de 2015-16)

\begin{tabular}{|c|c|c|c|c|c|c|c|}
\hline \multirow{2}{*}{ Fonte de Variação } & \multicolumn{7}{|c|}{ Quadrado Médio } \\
\hline & ALT & AREA & VOL & DEN & NRP & CRP & CIRO \\
\hline Bloco & $0,006^{\mathrm{ns}}$ & $0,029^{\mathrm{ns}}$ & $0,196^{\mathrm{ns}}$ & $6205,9^{\mathrm{ns}}$ & $87,3^{\mathrm{ns}}$ & $13,06^{\mathrm{ns}}$ & $0,202 *$ \\
\hline $\mathrm{N}^{\circ}$ Ramos ortotrópicos & $0,024^{\mathrm{ns}}$ & $0,533 *$ & $2,213 *$ & $312542,5^{*}$ & $27519,0^{*}$ & $25,03^{\mathrm{ns}}$ & $0,095^{\text {ns }}$ \\
\hline Resíduo & 0,007 & 0,050 & 0,184 & 5205,8 & 76,3 & 33,12 & 0,034 \\
\hline $\mathrm{CV}(\%)$ & 4,97 & 9,50 & 10,93 & 15,53 & 7,35 & 7,93 & 3,30 \\
\hline Média & 1,67 & 2,36 & 3,93 & 464,50 & 118,79 & 72,59 & 5,60 \\
\hline \multirow{2}{*}{ Fonte de Variação } & \multicolumn{7}{|c|}{ Quadrado Médio } \\
\hline & CIRP & ANG & NRO & NFR & NG & AFR & PROD \\
\hline Bloco & $0,154^{\mathrm{ns}}$ & $5,78^{\mathrm{ns}}$ & $0,47^{\text {ns }}$ & $0,11^{\mathrm{ns}}$ & $3,99 *$ & $7905,1^{\mathrm{ns}}$ & $7,56^{\mathrm{ns}}$ \\
\hline $\mathrm{N}^{\circ}$ Ramos ortotrópicos & $0,162^{\mathrm{ns}}$ & $13,08^{\mathrm{ns}}$ & $2,09 *$ & $3,86^{*}$ & $10,53^{*}$ & $107330,3^{*}$ & $807,17 *$ \\
\hline Resíduo & 0,098 & 11,94 & 0,47 & 0,63 & 1,43 & 14567,8 & 24,92 \\
\hline $\mathrm{CV}(\%)$ & 7,99 & 10,79 & 7,71 & 9,43 & 6,43 & 17,92 & 11,20 \\
\hline Média & 3,92 & 32,02 & 8,94 & 8,43 & 18,62 & 673,48 & 45,55 \\
\hline
\end{tabular}

* significativo e ${ }^{\text {ns }}$ não significativo pelo teste de $\mathrm{F}$ a $5 \%$ de probabilidade.

Rev. Ceres, Viçosa, v. 65, n.5, p. 415-423, set/out, 2018 

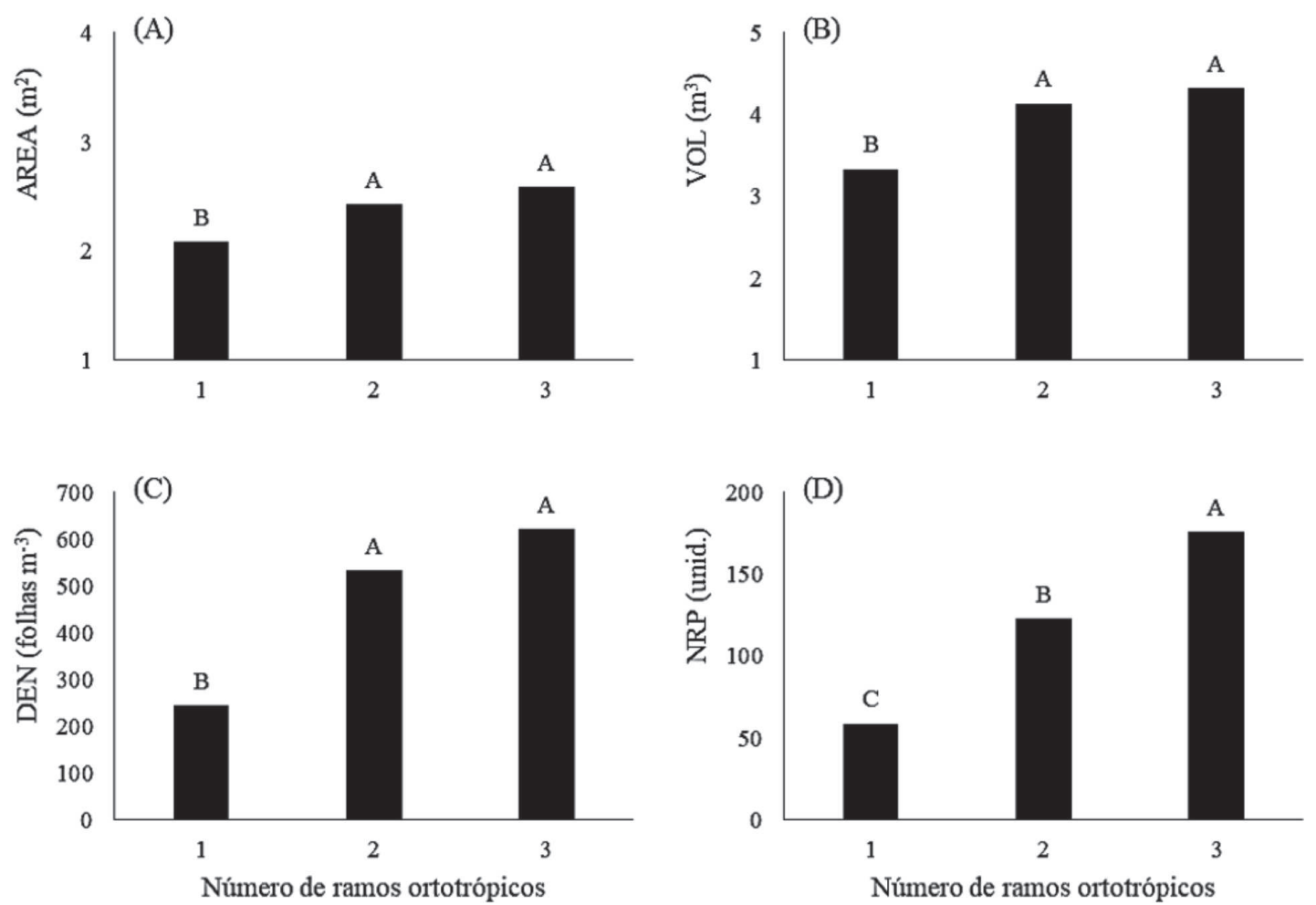

Figura 1: Área da copa (A), volume da copa (B), densidade de enfolhamento (C) e número de ramos plagiotrópicos (D), em função do número de ramos ortotrópicos, em plantas de cafeeiro arábica Catuaí Vermelho IAC44 (Santa Teresa,ES, safra de 2015-16). Médias seguidas pela mesma letra não diferem entre si pelo teste de Tukey, a 5\% de significância.
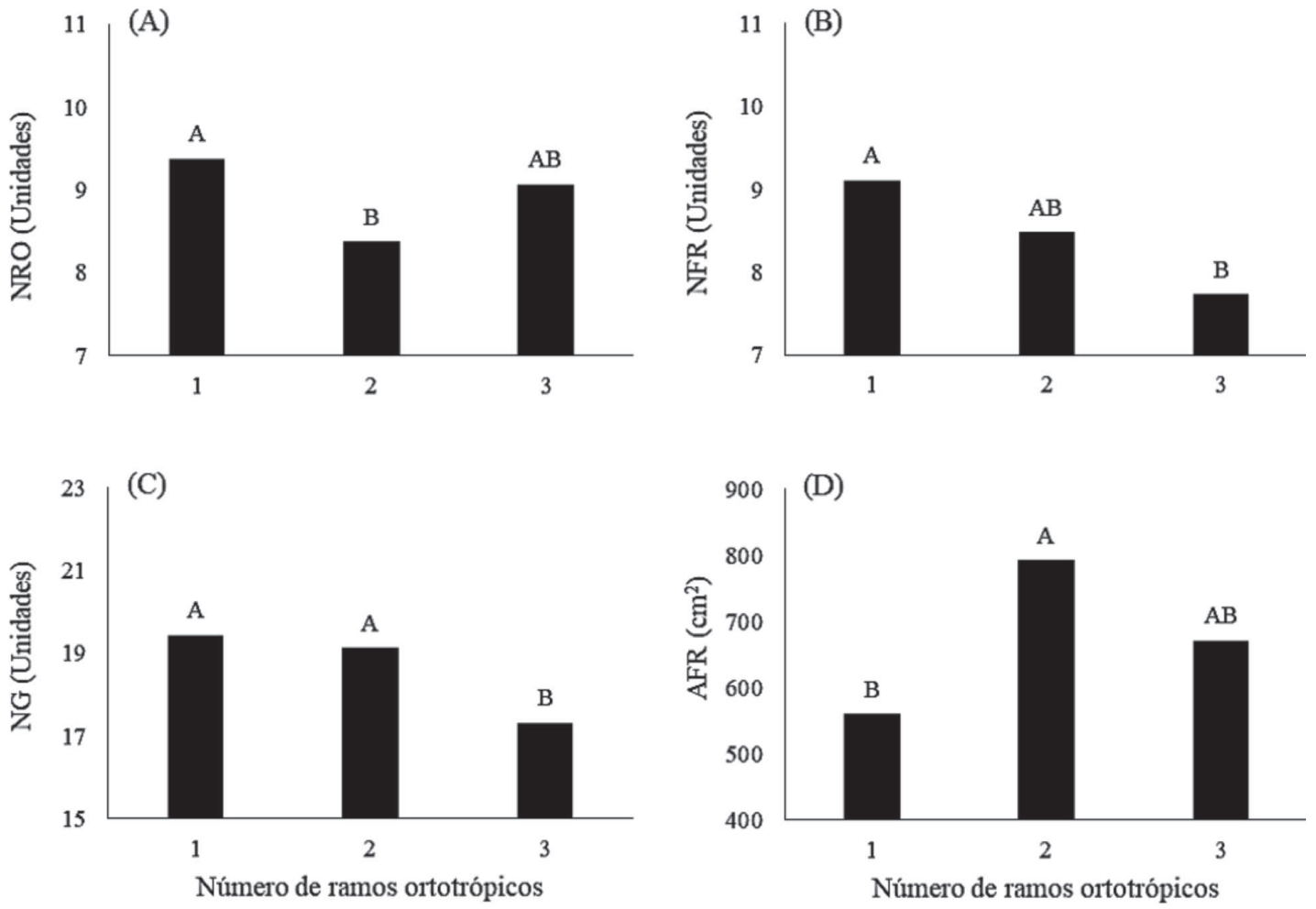

Figura 2: Número médio de rosetas por ramo plagiotrópico (A), número médio de frutos por roseta (B), número médio de nós (C) e área foliar do ramo plagiotrópico (D), em função do número de ramos ortotrópicos em plantas de cafeeiro arábica Catuaí Vermelho IAC44 (Santa Teresa, ES, safra de 2015-16). Médias seguidas pela mesma letra não diferem entre si pelo teste de Tukey, a 5\% de significância. 
al. (2001) que, quanto menor o ângulo de inserção dos plagiotrópicos no ramo ortotrópico, maior é o vigor vegetativo dessas plantas e maior é a probabilidade de bons índices de produção. De acordo com Avelar et al. (2013), o ângulo de inserção pode atuar na disposição dos ramos plagiotrópicos ao longo da copa, bem como na denominação do formato dessa copa.

Foram observados maior número de rosetas (NRO), em ramos plagiotrópicos de plantas com um ramo ortotrópico, e, menor NRO, em plantas com dois ramos verticais (Figura 2A). Verificou-se maior número de frutos por roseta (NFR), em ramos plagiotrópicos de plantas com um ramo ortotrópico, menor em plantas com três ramos verticais (Figura 2B). Esses resultados embasam a maior proporção de frutos em ramos plagiotrópicos de plantas com um ramo ortotrópico. Porém, vale ressaltar que o número de frutos por roseta de plantas com dois ramos foi estatisticamente semelhante ao de plantas com um e com três ramos ortotrópicos, respaldando que os ramos plagiotrópicos das plantas com dois ramos foram capazes

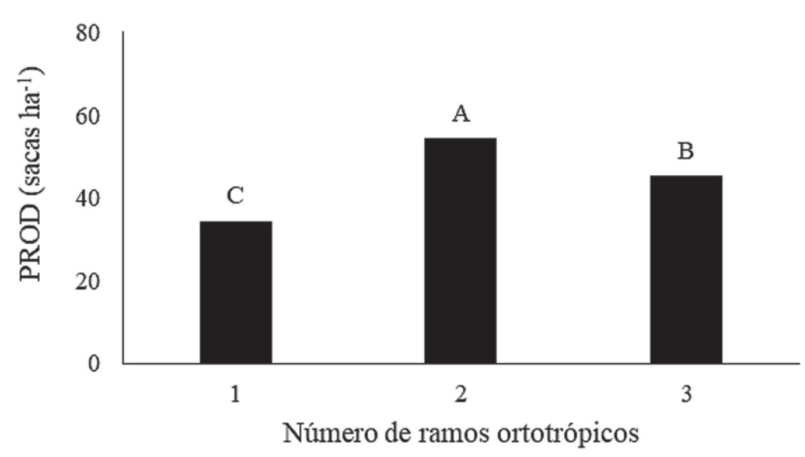

Figura 3: Produção de café beneficiado por hectare (PROD; sacas ha $\left.{ }^{-1}\right)$, em função do número de ramos ortotrópicos em plantas de cafeeiro arábica Catuaí Vermelho IAC44 (Santa Teresa,ES, safra de 2015-16). Médias seguidas pela mesma letra não diferem entre si pelo teste de Tukey, a 5\% de significância. de formar rosetas com uma quantidade considerável de frutos, além de maior proporção de folhas em seus ramos plagiotrópicos (Figura 2D), o que contribui para o metabolismo responsável por sustentar a safra vigente e, possivelmente, para a diminuição de desgastes para a safra futura.

Almeida (2015) relatou diminuição do número de frutos por roseta com o aumento do adensamento entre plantas, na linha, do cafeeiro arábica, porém não verificou variação do número de rosetas do ramo plagiotrópico. É provável que a diminuição do número de frutos por roseta em ramos plagiotrópicos de plantas com três ramos ortotrópicos tenha ocorrido em função da menor profusão floral (Cannell, 1985). Essa constatação também pode ser vista como efeito do autossombreamento, em plantas com três ramos.

O número de nós (NG) dos ramos plagiotrópicos foi menor em plantas com três ramos ortotrópicos do que em plantas com um ou dois ramos (Figura 2C). Um dos efeitos do sombreamento em plantas de café, ou até mesmo do autossombreamento ocasionado pelo adensamento (nesse caso, possivelmente em função do maior número de ramos ortotrópicos por planta), consiste na diminuição do número de nós no ramo plagiotrópico (Montoya et al., 1961; Castillo \& López, 1966), que pode interferir diretamente na produtividade do cafeeiro (Muschler, 1997; DaMatta, 2004a, 2004b).

Como já relatado, plantas com dois ramos ortotrópicos apresentaram maior área foliar total do ramo plagiotrópico (AFR), enquanto a menor AFR foi observada em plantas com um ramo ortotrópico (Figura 2D). A área foliar do ramo plagiotrópico de plantas com três ramos ortotrópicos não diferiu estatisticamente dos demais tratamentos (Figura 2D). O aumento da AFR pode favorecer o enfolhamento da copa e condicionar um microclima favorável às trocas gasosas, o que se mostra extremamente relevante

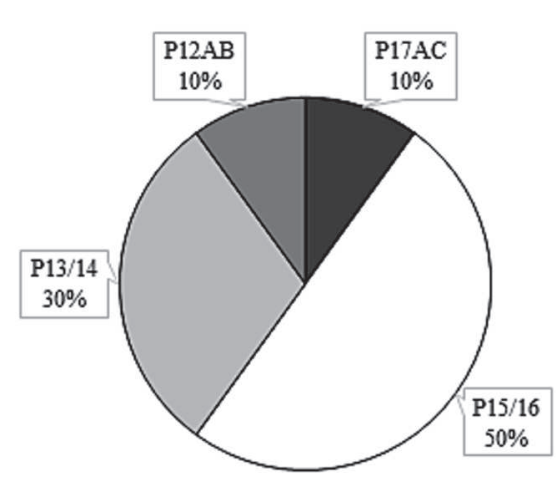

1 Ramo ortotrópico

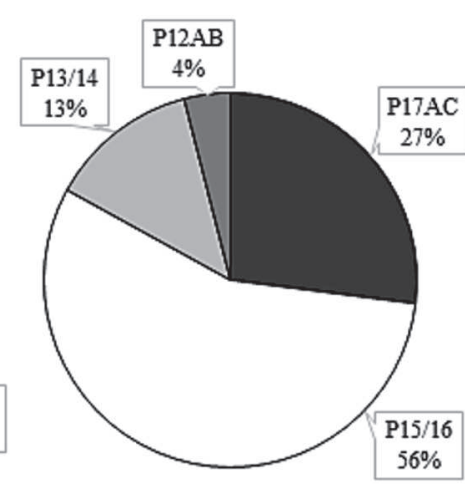

2 Ramos ortotrópicos

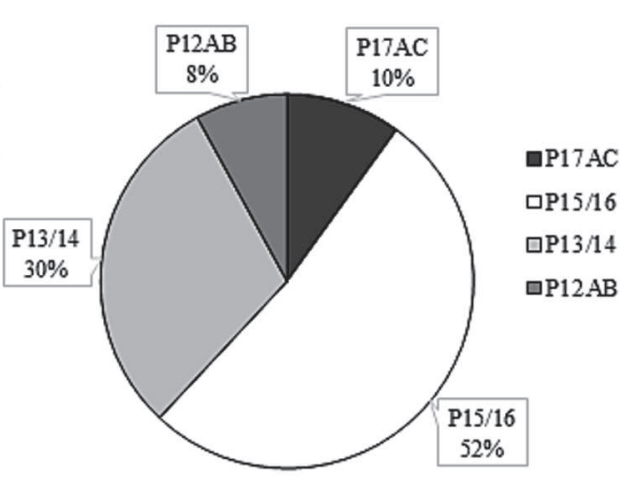

3 Ramos ortotrópicos

Figura 4: Distribuição média percentual de grãos de café nas classes de peneiras 17 acima (P17AC), peneiras 15+16 (P15/16), peneiras 13+14 (P13/14), peneiras 12 abaixo (P12AB), em função do número de ramos ortotrópicos em plantas de cafeeiro arábica Catuaí Vermelho IAC44 (Santa Teresa, ES, safra de 2015-16).

Rev. Ceres, Viçosa, v. 65, n.5, p. 415-423, set/out, 2018 
para o manejo de plantas. Além disso, pode influenciar positivamente a produtividade sem necessariamente ocasionar depauperamento excessivo das plantas.

Ao analisar a produção de café beneficiado por hectare (PROD), observou-se diferenciação estatística entre os tratamentos, sendo a maior produção obtida em plantas com dois ramos e, a menor, em plantas com um ramo ortotrópico (Figura 3). Essa superioridade de produção em função do manejo com dois ramos ortotrópicos, para a referida safra, foi favorecida por diversos fatores, dentre os quais ressaltam-se as características favoráveis da arquitetura da copa (área e volume de copa, densidade de enfolhamento, o número e o comprimento do ramo plagiotrópico, o comprimento dos internódios dos ramos plagiotrópicos e ortotrópicos, o número de nós e a área foliar dos ramos plagiotrópicos). Pode-se dizer que essas características, possivelmente, tenham favorecido a formação de microclima no dossel dessas plantas, capaz de melhorar aspectos fisiológicos e bioquímicos, embasando estas considerações nas observações de DaMatta \& Rena (2002), DaMatta (2004a), Lunz (2006) e Righi et al. (2007).

A produção de café, menor no tratamento com três ramos ortotrópicos do que no tratamento com dois (Figura 3), pode ser fruto da ocorrência de autossombreamento já relatado, certamente por causa do maior enfolhamento e do adensamento de copa, ocasionados pelo aumento do número de ramos plagiotrópicos e de folhas. Relatos mostram que o maior adensamento entre plantas (nesse caso, na própria planta) (Andrade et al., 2014) e o autossombreamento na copa das plantas (Nascimento et $a l ., 2006)$ são capazes de reduzir o aproveitamento da radiação fotossinteticamente ativa, resultando em menores produtividades por plantas; o que pode ser utilizado para embasar a produção de café no tratamento com três ramos ortotrópicos.

As plantas do tratamento com um ramo ortotrópico dispuseram de menor número de ramos plagiotrópicos; maior exposição às condicionantes ambientais (essas plantas podem estar mais expostas a variações da temperatura, da radiação solar e da umidade relativa do ar, por causa da menor arquitetura de copa); e, possivelmente, maior exaurimento dos órgãos fotossintetizantes. Todas essas características, atuando de forma conjunta, resultaram em menor produção no tratamento com um ramo ortotrópico e em condição favorável para ocorrência de maiores efeitos bienais de produção. Vale ressaltar que os cafeeiros dos cultivares Catuaí podem apresentar depauperamento precoce, decorrente do atendimento à demanda metabólica dos frutos, em função de cargas elevadas de produção (Nazareno \& Mendes, 2001). Esse efeito pode ser minimizado pela condução do cafeeiro arábica com mais de um ramo ortotrópico por planta.
Além da produção superior, em função do tratamento com dois ramos ortotrópicos, também pode ser observado aumento das proporções de grãos em peneiras com malhas maiores, em que a proporção de grãos retidos em peneiras P15-16 e superiores foi de $83 \%$, contra $62 \%$, no manejo com três ramos, e $60 \%$, no manejo com um ramo ortotrópico. Vale ressaltar que a proporção de grãos em peneiras 17 e acima, no manejo com dois ramos, foi de $27 \%$, o que representa mais que o dobro do observado nos outros dois tipos de manejo. Outro ponto importante foi a percentagem de grãos pequenos, em que plantas com dois ramos ortotrópicos apresentaram menor percentagem dessa classe de grãos (Figura 4).

Essas características de tamanho de grãos correlacionam-se com aspectos relacionados com o preço e, até mesmo, com a qualidade de bebida. Nesse caso, as melhores características de classificação de grãos podem ser observadas em plantas com dois ramos ortotrópicos (Figura 4). A padronização da massa de grãos é muito importante no processo de seca e torra, de modo a deixar o procedimento mais uniforme, o que influencia diretamente a qualidade da bebida (Rodrigues et al., 2014).

Dessa forma, com base no conjunto de características avaliadas, foi possível perceber que diversas características da arquitetura da copa e da produção do cafeeiro arábica foram significativamente influenciadas pela alteração do número de ramos ortotrópicos por planta.

São necessários mais estudos acerca dessa técnica e ao longo de mais safras produtivas, a fim de se elucidar outros efeitos em diferentes sistemas de manejo (cultivares, adubação, irrigação, fitossanidade, entre outros), bem como a análise conjunta dos fatores.

\section{CONCLUSÕES}

A condução do cafeeiro arábica com dois ramos ortotrópicos possibilita maior produção de café beneficiado, por hectare, e aumenta a distribuição percentual de grãos em malhas maiores, quando nas condições do estudo e na primeira safra produtiva após a recepa e a implementação dos tratamentos.

O manejo com dois ou três ramos ortotrópicos por planta resulta em aumentos da área e do volume de copa, da densidade de enfolhamento e da área foliar dos ramos plagiotrópicos.

\section{REFERÊNCIAS}

Almeida WL (2015) Respostas morfofisiológicas e de produtividade de cultivares de Coffea arabica L. em função da variação do espaçamento na linha de plantio. Dissertação de Mestrado. Universidade Federal de Viçosa, Rio Paranaíba. 44p.

Alves JD, Paglis CM, Livramento DE, Linhares SSD, Becker FB \& Mesquita AC (2011) Source sink manipulations in Coffea arabica L. and its effect on growth of shoots and root system. Ciência e Agrotecnologia, 35:956-964. 
Andrade WEB, Guimarães PTG, Faquin V \& Guimarães RJ (2014) Produtividade do cafeeiro arábica em condições de adensamento, no noroeste fluminense. Coffee Science, 9:090-101.

Avelar RC, Botelho CE, Silva FM, Dias REBA, Santos MC \& Meirelles AL (2013) Determinação de características desejáveis do cafeeiro (Coffea arabica L.) para a colheita mecanizada. In: $8^{\circ}$ Simpósio de pesquisa dos cafés do Brasil, Salvador. Anais, Embrapa Café. p.1-5.

Braccini AL, Scapim CA, Vidigal Filho OS, Braccini MCL, Borges SC \& Albrecht LP (2005) Características agronômicas e produção de frutos e de grãos em resposta ao aumento da densidade populacional do cafeeiro. Acta Scientiarum. Agronomy, 27:269279 .

Cannell MGR (1985) Physiology of the coffee crop. In: Clifford MN \& Willson KC (Eds.) Coffee. Westport, Springer. p.108134

Carvalho CHM, Colombo A, Scalco MS \& Morais AR (2006) Evolução do crescimento do cafeeiro (Coffea arabica L.) irrigado e não irrigado em duas densidades de plantio. Ciência e Agrotecnologia, 30:243-250.

Carvalho GR, Botelho CE, Rezende JC, Ferreira AD, Cunha RL \& Pedro FC (2013) Comportamento de progênies F4 de cafeeiros arábica, antes e após a poda tipo esqueletamento. Coffee Science, 8:33-42.

Castillo ZJ \& López AR (1966) Nota sobre el efecto de la intensidad de la luz en la floración del café. Cenicafé, 17:51-60.

CONAB - Companhia Nacional de Abastecimento (2017) Acompanhamento da safra brasileira: café. Brasília, Conab. 84p.

Cunha RL, Mendes ANG, Guimarães RJ \& Carvalho J (1999) Efeito da época, altura de poda e adubação foliar na recuperação de cafeeiros (Coffea arabica L.) depauperados. Ciência e Agrotecnologia, 23:222-226.

DaMatta FM (2004a) Ecophysiological constraints on the production of shaded and unshaded coffee: a review. Field Crops Research, 86:99-114.

DaMatta FM (2004b) Explorando a tolerância à seca em café: uma abordagem fisiológica com algumas contribuições para o melhoramento de plantas. Revista Brasileira de Fisiologia Vegetal, 16:01-06.

DaMatta FM \& Rena AB (2002) Ecofisiologia de cafezais sombreados e a pleno sol. In: Zambolim L (Ed.) O estado da arte de tecnologias na produção de café. Viçosa, Editora UFV. p.93135

DaMatta FM, Ronchi CP, Maestri M \& Barros RS (2007) Ecophysiology of coffee growth and production. Brazilian Journal of Plant Physiology, 19:485-510.

Fazuoli LC (1999) Cultivares de café IAC. O Agronômico, 51: 0507.

Ferreira DF (2011) SISVAR: A computer statistical analysis system. Ciência e Agrotecnologia, 35:1039-1042.

IAC - Instituto Agronômico de Campinas (2014) Resultados do programa de melhoramento genético do café arábica do IAC Disponível em: http://www.iac.sp.gov.br/areasdepesquisa/cafe/ centrocafe4.php. Acessado em: 03 de fevereiro de 2017.

Lunz AMP (2006) Crescimento e produtividade do cafeeiro sombreado e a pleno sol. Tese de Doutorado. Escola Superior de Agricultura "Luiz de Queiroz", Piracicaba. 94p.

Matiello JB, Santinato R, Garcia AWR, Almeida SR \& Fernandes DR (2002) Podas. In: Matiello JB, Santinato R, Garcia AWR, Almeida SR \& Fernandes DR (Eds.) Cultura de café no Brasil: novo manual de recomendações. Rio de Janeiro, MAPA/ PROCAFÉ. p. 256-274.
Matiello JB, Garcia AWR, Almeida SR \& Fernandes DR (2010) Cultura de café no Brasil: manual de recomendações. $3^{\mathrm{a}}$ ed. Rio de Janeiro, Bom Pastor. 542p.

Montoya LA, Sylvain PG \& Umaña R (1961) Efeito da intensidade da luz e da adubação nitrogenada sobre o equilíbrio de diferenciação do crescimento em Coffea arabica L. Café, 3:97-104

Mota ACV, Nick JA, Yorinori GT \& Serrat BM (2006) Distribuição horizontal e vertical da fertilidade do solo e das raízes de cafeeiro (Coffea arabica L.) cultivar Catuaí. Acta Scientiarum. Agronomy, 28:455 463.

Muschler R (1997) Sombra ou sol para a produção de café ecologicamente sustentável, um resumo dos principais fatores ambientais. In: $3^{a}$ Semana Científica Centro Agronômico Tropical del Investigación y Enseñanza, Turrialba. Anais, CATIE. p.109-112.

Nascimento EA, Oliveira LEM, Castro EM, Delúfilho N, Mesquita AC \& Vieira CV (2006) Alterações morfofisiológicas em folhas de cafeeiro (Coffea arabica L.) consorciado com seringueira (Hevea brasiliensis Muell. Arg.). Ciência Rural, 36:852857.

Nazareno A \& Mendes G (2001) Cultivares com potencialidade para lavouras irrigadas. In: Santos CM (Ed.) Irrigação da cafeicultura no Cerrado: Palestras. Uberlândia, UFU. p.125-135

Oliveira E, Silva FM, Guimarães RJ \& Souza ZM (2007) Eliminação de linhas em cafeeiros adensados por meio semimecanizado. Ciência e Agrotecnologia, 31:1826-1830.

Pavan MA, Chaves JCD \& Androcioli-Filho A (1994) Produção de café (Coffea arabica L.) var. Caturra em função da densidade de plantio, adubação e tratamento fitossanitário. Turrialba, 44:227231.

Pereira SP, Guimarães RJ, Bartholo GF, Guimarães PTG \& Alves JD (2007) Crescimento vegetativo e produção de cafeeiros (Coffea arabica L.) recepados em duas épocas, conduzidos em espaçamentos crescentes. Ciência e Agrotecnologia, 31:643649.

Pereira SP, Bartholo GF, Baliza DP, Sobreira FM \& Guimarães RJ (2011) Crescimento, produtividade e bienalidade do cafeeiro em função do espaçamento de cultivo. Pesquisa Agropecuária Brasileira, 46:152 160 .

Pezzopane JEM, Castro FS, Pezzopane JRM \& Cecílio RA (2012) Agrometeorologia: aplicações para o Espírito Santo. Alegre, CAUFES. $174 \mathrm{p}$.

Prezotti LC, Gomes JA, Dadalto GG \& Oliveira JA (2007) Manual de recomendação de calagem e adubação para o Estado do Espírito Santo: $5^{\text {a }}$ aproximação. Vitória, SEEA/INCAPER/ CEDAGRO. 305p

Reis PR \& Cunha RL (2010) Café arábica: do plantio à colheita. Lavras, EPAMIG. 896p.

Rena AB, Nacif AP, Guimarães PTG \& Pereira AA (1994) Fisiologia do cafeeiro em plantios adensados. In: $1^{\circ}$ Simpósio Internacional sobre Café Adensado, Londrina. Anais, IAPAR. p.71-85.

Righi CA, Bernardes MS, Lunz AMP, Pereira CR, Dourado Neto D \& Favarin JL (2007) Measurement and simulation of solar radiation availability in relation to the growth of coffee plants in an agroforestry system with rubber trees. Revista Árvore, 31:195-207.

Rodrigues WP, Vieira HD, Barbosa DHSG, Sousa Filho GR \& Partelli FL (2014) Agronomic performance of arabica coffee genotypes in northwest Rio de Janeiro State. Genetics and Molecular Research, 13:5664-5673. 
Ronchi CP, Sousa Júnior JM, Ameida WL, Souza DS, Silva NO, Oliveira LB, Guerra AMNM \& Ferreira PA (2015) Morfologia radicular de cultivares de café arábica submetidas a diferentes arranjos espaciais. Pesquisa Agropecuária Brasileira, 50:187195

Sera GH, Sera T, Androcioli Filho A, Azevedo JA, Altéia MZ \& Colombo LA (2001) Herança da característica erecta (Er) da ramificação plagiotrópica e sua relação com o vigor vegetativo em população F2 do cruzamento "Catuaí Erecta" x "IAPAR59'. In: $2^{\circ}$ Simpósio de Pesquisa dos Cafés do Brasil, Vitória. Anais, Embrapa Café. p.1357-1362.
Thomaziello EA, Oliveira EG, Toledo Filho JA \& Costa TE (1998) Cultura do café. Campinas, CATI. 57p. (Boletim técnico, 193).

Thomaziello EA \& Pereira SP (2008) Poda e condução do cafeeiro arábica. Campinas, IAC. 39p. (Boletim Técnico, 203).

Verdin Filho AC, Volpi PS, Ferrão MAG, Ferrão RG, Mauri AL, Fonseca AFA, Tristão FA \& Andrade Júnior S (2016) New management technology for arabica coffee: the cyclic pruning program for arabica coffee. Coffee Science, 11:475-483. 